\title{
NOTAS \\ PARA UN ESTUDIO SISTEMATICO \\ DE LA \\ LITERATURA LATINA
}

Jaime Siles

Universidad de Salainanca

0.1. Reuno aquí una serie de notas, destinadas, en su mayor parte, a trazar las líneas maestras de lo que podría ser un estudio, sistemático y sistematizado, de la literatura latina.

Algunas de las indicaciones que aquí hago (p. e. la que ocupa el punto 1.1.) pueden parecer $-y$ no se me oculta- excesivamente vagas y generales. Sin embargo -y ésta es la razón de que las introduzca - desempeñan una función que, aunque tangencial, resulta absolutamente necesaria como introducción global al conjunto, cuyos rasgos distintivos se intenta precisar.

Las cuestiones que apunto intentan subrayar la necesidad de ver y entender la literatura latina no sólo como la sucesión cronológica de una producción unida por el carácter de su lengua, sino también -y sobre todo-como un Sistema Literario, que, a lo largo de su historia y en el interior de sus estructuras, experimenta una variabilidad formal. Los puntos, en fin, que aquí se tratan son: I. El Concepto de Literatura Latina (1.1.: El término "literatura"; 1.2. El término "literatura" aplicado a la latina; 1;3; Límites, espacios y cronología de la literatura latina), II. Historia Literaria (2.1. Problemática de una Historia de la literatura latina; 2.2. La Retórica, los géneros literarios y la morfología de la literatura latina: consideración general) y III. Notas para un estudio sistemático de la literatura latina, cuya denominación da título al presente trabajo. 
JAIME SILES

\section{EL CONCEPTO DE LITERATURA LATINA:}

\subsection{El término "Literatura”:}

En las líneas que siguen, intentaremos definir, en lo posible, lo que la literatura latina es y lo que, como tal, se nos presenta. Pero eso no puede hacerse, sin haber dado, previamente, una respuesta elaborada a la pregunta de base que aquí se nos plantea y que no es otra que la de iqué es literatura? ${ }^{1}{ }^{*}$. Pues bien, para responder a esa pregunta, comenzaremos por considerar la historia de dicho vocablo, que, como casi todos los "que expresan la actividad intelectual y artística del hombre (. . .) se presenta fuertemente afectada por el fenómeno de la polisemia"2.

El vocablo "literatura" $\overline{3}$ es un derivado del término latino litteratura, que transcribe, según Quintiliano (I.O., II, 1.4), el griego $\gamma$ p $\alpha \mu \mu \alpha \tau \kappa \dot{n}$. Y, como tal, pasó hacia finales del siglo XV al español ("literatura"), al francés (littérature), al italiano (letteratura) y al inglés (literature), siendo más tardía la documentación de dicho vocablo en alemán -donde está atestiguado en el siglo XVI- y en ruso, donde no está testimoniado hasta el siglo XVIII.

El término litteratura (derivado de littera) servía en latín para designar conceptos tales como escritura, gramática, filología, alfabeto, ciencia, erudición y cuanto, en general, se refiriese a -o tuviera relación con- la littera y las litterae, incluyendo en éstas, asimismo, el arte de escribir o de leer. Esta concepción de la "literatura" -en el sentido latino- se mantuvo hasta el siglo XVIII. Así, para Montaigne (Essais, II, 19), "literatura" es la ciencia en general y, para Voltaire, 1a cultura del hombre de letras". En el siglo XVIII, en cambio, el vocablo "literatura" y el adjetivo "literario", de él derivado, experimentan una transformación y a lo que hoy denominamos "literatura" se le llama entonces poesia o elocuencia. En la segunda mitad de dicho siglo, el término "literatura" ya no significa el conjunto del saber o la cultura específica del hombre de letras, sino que alude a una actividad, muy concreta, de éste: el "objeto o conjunto de objetos que se puede estudiar"5. Así el vocablo Literatur, tal y como lo emplea Lessing en sus Briefe die neueste Literatur betreffend, publicadas entre 1759 y 1765 , sirve para designar un conjunto de obras literarias. Y, a finales del tercer cuarto de dicho

1 Cf. H. RÜDIGER, "Was ist Literatur?", Literatur und Dichtung, Stuttgart, 1973, pp. 26-32.

2 Cf. V.M. DE AGUILAR e SILVA, Teorla de la Literatura, Versión española de V. GARCIA YEBRA, Madrid, 1975, pág. 11.

3 Cf. R. ESCARPIT, "La définition du terme littérature", Actes du III Congrés de l'Association Internationale de Littérature Comparée, The Hague, 1962, pp. 77-89.

4 Cf. De AGUIAR e SILVA, op. cit., pp.12

5 Cf. De AGUIAR, e SILVA, op. cit., pp.12 


\section{NOTAS PARA UN ESTUDIO SISTEMATICO}

siglo, el término literatura, modificado ya por un adjetivo determinativo ("espanola", "francesa", "inglesa", etc.) que lo concretiza, es usado para referirse al conjunto de obras literarias de un país. Ejemplo de ello es la publicación en 1772 de la Storia della letteratura italiana de Gerolamo Tiraboschi.

En la penúltima década del siglo XVIII, el vocablo "literatura" se polariza en una dirección: la de designar "el fenómeno literario en general y ya no circunscrito a una literatura nacional en particular", , sino "hacia la noción de "literatura" como creación estética, como "categoría intelectual y forma específica de conocimiento"7, que es el significado que dicho término tiene en la obra de Marmontel, Eléments de littérature (1787) y en la Mme de Staël, De la littérature considérée dans ses rapports avec les institutions sociales (1800).

La transformación del concepto de "literatura", a lo largo del siglo XVIII, es consecuencia de: a), por un lado, la especialización del término "ciencia", que como resultado del desarrollo de la ciencia inductiva y experimental, ya no es posible incluir dentro de la denominación general de "literatura" y b), por otro, de que, en dicho siglo, "se asiste a un amplio movimiento de valorización de los géneros literarios en prosa, desde la novela hasta el periodismo, haciéndose necesarias, por consiguiente, una designación genérica que pudiera abarcar todas las manifestaciones del arte de escribir" ${ }^{\prime 8}$ y que fue la de literatura.

Los siglos XIX y XX continuaron modificando y ampliando las acepciones del vocablo. Y asi "literatura" sirvió para designar" tanto el "conjunto de la producción literaria de una época o de una región" como el "conjunto de obras que se particularizan y cobran forma especial ya por su origen, ya por su temática o por su intención (literatura femenina, literatura de terror, literatura revolucionaria, literatura de evasión)"; tanto la "bibliografia existente acerca de un tema determinado", como la "Retórica" o -por elipsis-la historia de la literatura o - por metonimia-manual de historia de la literatura. Por último "literatura" significa, también -y este es el sentido que, desde un punto de vista universitario, suele darse al término- "conocimiento organizado del fenómeno literario ${ }^{10}$. Esta pluralidad de significaciones es la que, por otra parte, recoge el Diccionario de la Real Academia Española, que, para el término literatura, dá las siguientes acepciones: "1. Arte bello que emplea como instrumento la palabra. Comprende no sólamente las producciones poéticas, sino también todas aquellas obras en que caben elementos estéticos, como las oratorias, históricas y didácticas; 2 . Teoría de las composiciones literarias; 3 . Conjunto de las producciones literarias de una nación, de una época, de un género; 4 . Por extensión, conjunto de obras que versan sobre un arte o ciencia (...) 5. Suma de conocimientos adquiridos con el

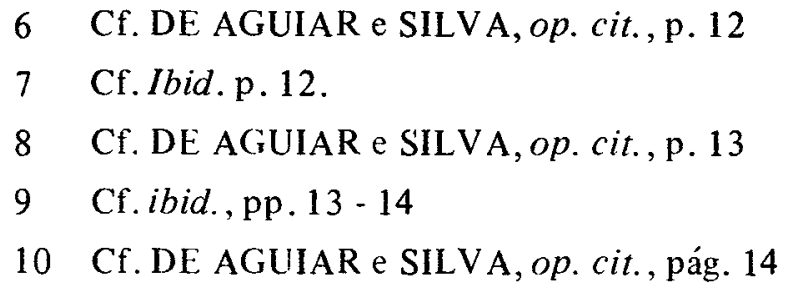




\section{JAIME SILES}

estudio de las producciones literarias; y en sentido más lato, instrucción general en éste y cualquiera otros de los distintos ramos del saber humano"11.

Esta pluralidad de significaciones y la historia de la evolución semántica del término nos hacen ver cuán difícil es establecer "un concepto incontrovertido de literatura" 12 y lo extremadamente peligroso que resulta cualquier intento de definición. Es lo que, con razón, indica Wellek ${ }^{13}$, cuando a las preguntas "¿QQué es literatura? ¿qué no lo es? ¿Cuál es la naturaleza de la literatura? "reponde: "Por sencillas que parezcan, estas preguntas, rara vez se contestan claramente". $\mathrm{Y}$ es que responder a esas preguntas supone, en cierto modo, elaborar una teoría general de la literatura, cuestión ésta que no entra dentro de nuestro cometido. Porque como hemos visto, la noción de "literatura" no sólo ha sufrido una notable transformación a lo largo de la historia, sino que, además, el problema de su definición se complica, todavía más, debido a la pluralidad de significaciones que el término "literatura" dentro de sí acoge. Piénisese, por ejemplo, en que "literatu$r a$ " es tanto "el conjunto de la producción literaria de una época o región" como la serie de características y particularidades que hacen que una determinada obra sea considerada como "literatura". Así, Wellek ${ }^{14}$ no considera "literatura" más que las obras en que predomine la función estética aunque -dice-cabe admitir la existencia de elementos estéticos tales como estilo y composición en obras que persiguen una finalidad completamente distinta, no estética, como tratados científicos, disertaciones filosóficas, libelos políticos, sermones"; y Roland Barthas ${ }^{15}$. sostiene que "a la vez proposición insistente de sentido, y sentido obstinadamente fugitivo, la literatura no es más que un lenguaje, es decir, un sistema de signos". Estas dos definiciones - que, indudablemente, son bastante amplias- resultan, precisamente por su alto grado de generalización, un tanto esquemáticas y, por tanto, aunque las dos tratan de responder a la pregunta ¿Qué es literatura?, ninguna de ellas sirve para aclararnos, plenamente y con satisfacción, la cuestión que nosotros tenemos planteada. Ambos críticos dan $-y$ esto es evidente- una definición, que parece válida para explicar el concepto "literatura" en sentido abstracto: En un sentido que, de modo paralelo a lo que entendemos por Lingü istica General, podría denominarse Literatura General. Y, por eso mismo, esa definición -que nos parece válida como explicación de lo que por "Literatura General" se entiende- nos parece, en cambio, excesivamente esquemática a la hora de definir una literatura concreta como la latina. De ahí que nos veamos obligados a buscar una definición de "literatura" que sea más concreta y que

11 Cf. al respecto, M.A. GARRIDO GALLARDO, Introducción a la teoría de la literatura, Madrid, 1976, pág. 23.

12 Cf. DE AGUIAR e SILVA op. cit., pág. 14

13 Cf. R. WELLEK- A. WARREN, Teoria literaria, Versión española de J. M. GIMENO, Madrid, 1969, pág. 24.

14 WELLEK R. WARREN A. Op. cit., pág. 30.

15 R. BARTHES, Ensayos criticos, traducción de C. PUJOL, Barcelona, 1967, pág. 306. 


\section{NOTAS PARA UN ESTULIO SISTEMATICO}

nos permita establecer lo que por literatura latina se entiende.

\subsection{El término "literatura" aplicado a la latina:}

En el apartado anterior hemos visto la evolución semántica del término "literatura" y la pluralidad de acepciones que, a lo largo de la historia, este vocablo ha ido reuniendo. En las líneas que siguen intentaremos encontrar un criterio, que nos permita establecer lo que la literatura latina es. Dicho criterio no podrá basarse ni en definiciones excesivamente amplias -como lo son las de los teóricos de la llamada Literatura General-, ni en puntos de vista demasiado inscritos en la literatura contemporánea, como lo son los de parte de la crítica más reciente. Porque como advierte Eduard Norden ${ }^{16}$ : "Die antike Literatur unterscheidet sich in formaler Hinsicht von den Literaturen aller modernen Völker dadurch, dass sie einen unvergleichlich höheren Wert auf die Form der Darstellung legt". Dicho criterio tendrá, pues, que basarse - necesariamente- en esa "Form der Darstellung", que, por otra parte, corresponde al modo en que la Antigüedad Clásica respondía a la pregunta "¿Qué es literatura"? Pues bien, para la Antigüe dad Clásica, Literatura era "una serie de productos concretos (agrupables en "géneros"), resultados de una "imitación", que responde a una tipología de determinadas texturas lingüisticas y que se caracterizan unitariamente en virtud de una función social"17. De ahí que:

1) Como observa Norden ${ }^{18}$ : "Im Allgemeinen darf man sagen, dass es in Altertum dem Schriftsteller grössere Mühe machte, kunstlos als kuntsvoll zu schreiben; so stark war die Macht der Tradition, der Erziehung und vor allen der Anlage";

2) En la Antiguedad Clásica, toda obra supone una "causa formal" o arquetipo que se trata de imitar y que, en la mayoría de los casos, está constituido por a) el género literario al que dicha obra pertenece y b) por la tradición, en que dicha obra se inscribe.

Al ser esto asi, se comprenderá fácilmente que el conocimiento de la literatura latina -como el conocimiento de la Literatura de la Antigüedad Clásica en general - esté unido a -y condicionado por- la comprensión y el conocimiento de los géneros literarios, de su historia y de su constitución ${ }^{19}$. Por eso -y aunque Karl Büchner afirme que "Erst bei Ovid, der in der Pax Augusta aufwächst, kann man von einer eigentlichen "Literatur" sprechen" 20 -lo cierto es que sólo

16 NORDEN E., Die Antike Kunstprosa.' Vom VI. Jahrhundert v. Chr. bis in die Zeit der Renaissance, Darmstadt, 1974, Bd. I, pág. 1.

17 Cf. GARRIDO GALLARDO M.A., op. cit., pág. 29.

18 NORDEN, E. Die Antike Kunstprosa. . ., I, pp. 1-2.

19 Cf. al respecto, W. SCHADEWALDT, "Der Umfang des Begriffs der Literatur in der Antike", apud H. RUDIGER (Hrsg.), Literatur und Dichtung, pp. 12-25.

20 Cf. K. BÜCHNER, "Römische Geschichte und Geschichte der römischen Literatur", Aufstieg und Niedergang der römischen Welt, Berlin-New York, 1972., Bd. II. 2, pág. 773. 


\section{JAIME SILES}

puede hablarse de literatura latina por relación y por referencia a lo que, desde el punto de vista de la Antigüedad Clásica, constituía el conjunto de paradigmas y arquetipos que informaban el sistema de su literatura: los géneros literarios ${ }^{21}$. De modo que, teniendo en cuenta la posición de la literatura latina en el contexto de la Antigüedad ${ }^{22}$, puede concluirse que literatura latina es, en el sentido estricto (esto es, desde el punto de vista de los autores que la compusieron y de la sociedad que la hizo posible), toda obra, escrita en lengua latina y susceptible de ser clasificada dentro de alguno de los géneros literarios que la constituyen y la informan. Ahora bien, una concepción así dejaría fuera de la literatura latina una serie de textos que, aunque no propiamene literarios (en el sentido que antes hemos dado al término), son, en cambio, significativos desde un punto de vista cultural: así, por ejemplo, los tratados de arquitectura, de medicina, de gramática, de jurisprudencia, etc., que, sin embargo, forman parte del Schrifttum latino y que no sería justo ignorar. Es cierto, desde luego, que no todo lo escrito en lengua latina es literatura y que, por lo tanto, no todo puede ser considerado como tal, pero, en este punto, nuestro criterio tiene que ser más amplio y admitir, dentro del concepto de "literatura", no sólo las obras que se acomodan a los arquetipos conocidos por el nombre de géneros literarios, sino también aquellos textos epigráficos que, por reunir elementos formales de algunos de los géneros o por estar dotados de valor estético o por contener rasgos de un estilo formular, sí pueden considerarse incluidos dentro de lo que se entiende por "literatura"23. Y también, hay que incluir dentro del concepto de "Literatura latina" las obras de los llamados "escritores técnicos" y de los autores de tratados científicos, porque -como observa muy bien Löfstedt ${ }^{24}$ al responder a la pregunta "What parts of literature preserved in writing fall within the field of the history of literature?"- "We know, of course, that in the modern world we do not include, for example, scientific and technical literature; nor do we include, for example, works on natural science or philosophy unless they happen to be written in a particulary artistic or personal manner. In the sphere of ancient literature, howe$\mathrm{er}-$ and it is a point which we must bear in mind- the situation is quite different. Here we are accustomed - and rightly - to include whiting the field of literary history works on, for example, architecture, medicine, grammar,jurisprudence, and so on. There are various reasons for this. It is partly because so much,

21 Cf. K.SBOVODA, L'Esthétique d'Aristote, Brno, 1927 y J.C. GHIANO, Los géneros Literarios, Buenos Aires, 1961.

22 Cf. G. FUNAIOLI, "La letteratura latina nella cultura antica", Studi di Letteratura Antica. Spiritu e Forme, Figure e problemi della letterature clasiche, Vol. I, Bologna, 1946, pp. 1-34.

23 Cf. F.MARX, Aufsätze zur frühlateinischen Dichtung, Hildesheim, 1969, pág. 71; H. RAHN, Morphologie der antiken Literatur, Darmstadt, 1969, pp. 114-118; K. BÜCHNER, Humanitas Romana, Heidelberg, 1957, pág. 243.; R. CHEVALIER, Epigraphie et Littérature à Rome, Faenza, 1972, (Epigrafía e Antichità), págs. 7-10.

24 Cf. I:. LOFSTEDT, "The Background of Roman Literature", Roman Literary Portraits, Oxford, 1958, pp. 46-47. 


\section{NOTAS PARA UN ESTUDIO SISTEMATICO}

of ancient literature is lost that we must, addition to the fragments, also take account of the remotest outworks, so as to be able to reconstruct the whole in some degree. Partly, and more specially, because the link, the association between literature and scientific writing, still existed in antiquity (...)".

En fin, creemos que -después de toda esta serie de consideraciones- el concepto de literatura latina $\mathrm{o}$, al menos, de lo que por tal pensamos que hay que entender, ha quedado suficientemente explicitado. Sólo nos resta, pues, definir los límites cronológicos y espaciales en los que dicha literatura se ha desarrollado y transcurrido. Esto es lo que haremos en el apartado siguiente.

\subsection{Limites, Espacios y Cronologia de la Literatura Latina:}

1.3.1 La literatura latina - tal y como ha quedado definida en el apartado anterior - se nos presenta, por su amplitud precisamente, como un conjunto demasiado difícil de abarcar y, por lo tanto, de comprender. Es más: según la definición de "literatura latina", antes dada, cabrian dentro de la misma, tanto algunos textos epigráficos del siglo III a.C. como los escritos actuales que, redactados en latín, concurren al Certamen capitolinum, que el "Insituto di Studi Romani" de Roma convoca. Pues bien, como la literatura latina es uno de los aspectos de la Latinitas ${ }^{25}$ (concretamente, el de "conjunto de obras y escritores latinos") y como "literatura" es, también el "conocimiento organizado del fenómeno literario" 26 , vamos a intentar someter ese "conjunto de obras y escritores" -que es la literatura latina - a una de las formas posibles con que, para su "conocimiento organizado", disponemos: a su delimitación.

Al intentar establecer unos límites cronológicos y geográficos de la Literatura Latina, no pretendemos aislar a ésta del conjunto cultural del que forma parte, sino, por el contrario circunscribirla y referirla a ese todo, del que, precisamente, recibe su sentido y, dentro del cual, posee su significado y su función. La Literatura Latina es un significante de la civilización en que surgió y sólo dentro de $-\mathrm{y}$ por referencia a-dicha civilización tiene significado. Porque la literatura latina es, como se ha dicho, el "conjunto de obras y escritores latinos" y cada obra literaria "es un signo en el sistema de signos literarios, culturales, sociales de una determinada época o situación"27. Y lo que aquí intentamos determinar es, precisamente, los limites temporales y espaciales, entre $-\mathrm{y}$ por- los que dicho sistema de signos literarios transcurre. Así las cosas, podemos ya adelantar y, en par-

25 Cf. M. C. DIAZ Y DIAZ, "Latinitas". "Sobre la evolución de su concepto", Emerita, XIX (1951), pág. 49; vid, además, E. WOLFFLIN, "Uber die Latinität des Asinius Polio", Archiv für lateinische Lexikographie und Grammatik, 6 (1889), pp. 85-106 y Ch.

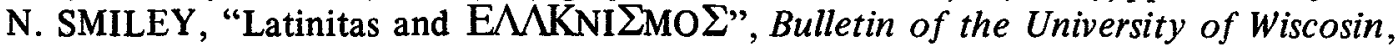
143 (1906), pp. 211-271.

26 Cf. supra 1.1.

27 Cf. M. A. GARRIDO GALlARDO, op. cit., pág. 123. 


\section{JAIME SILES}

te, establecer las siguientes consideraciones:

a) Desde un punto de vista cronológico, dicho sistema de signos literarios transcurre en el espacio temporal comprendido entre el siglo III a. C. -que es, cuando se inicia, propiamente, la formación y constitución de la lengua literaria latina - y el siglo $\mathrm{V} \mathrm{d}$. C., que es cuando se descompone la unidad cultural y politica, que servía de base a ese sistema de signos literarios. Estos serían, pues, los límites cronológicos de la literatura latina: 1) como fecha inicial, el siglo III, a. C. y 2) como fecha final, el siglo V d. C., aunque hay estudiosos -como Bardon ${ }^{28}$ - que no dudan en situar el comienzo de la decadencia de la literatura romana en una fecha mucho más antigua: la del $138 \mathrm{~d}$. C., a partir de la cual no hay más que -excepción hecha de Apuleyo- tratados de gramática o de jurisprudencia, comentarios de los autores considerados "clásicos", panegíricos y nomenclaturas históricas o geográficas. Sin embargo, trabajos como los de Curtius ${ }^{29}$, Auerbach ${ }^{30}$, y otros ${ }^{31}$, han probado que la literatura latina se ha mantenido y conservado más allá de esa frontera cronológica, que, como fecha tope, hemos puesto y que coincide con la caída del Imperio Romano. De modo que, aunque en sentido estricto-que es el que aquí hemos tenido en cuenta a la hora de establecer y fijar los límites cronológicos antes indicados- no puede hablarse de "literatura latina" con anterioridad a la constitución de la lengua literaria de Roma, ni con posterioridad a la desaparición de la unidad cultural $^{32}$ que hizo posible la existencia de ese sistema de signos literarios, hay, sin embargo, que -desde un punto de vista puramente lingüístico- considerar, como literatura latina también, las llamadas literatura latina medieval, humanistica o moderna, que, si bien sobrepasan los límites cronológicos antes citados, constituyen, no obstante, parcelas de estudio e investigación revestidas del máximo interés, no sólo filológico o lingüístico, sino también $-y$ sobre todo- cultural. La razón de que nosotros no las incluyamos aquí no es

28 Cf. H. BARDON, "L'appauvrissement des lettres latines", Les Empereurs et les lettres Latines d'Auguste à Hadrien, París, 1968, pág. 424 ss.

29 Cf. E. R. CURTIUS, Europäische Literatur und lateinisches Mittelalter, Bern, 1948; Hay traducción castellana de M. FRENK ALATORRE y A. ALATORRE, México 1955.

30 E. AUERBACH, Literatursprache und Publikum in der lateinischen Spätantike und im Mittelalter, Bern, 1958; existe traducción castellana de L. LOPEZ MOLINA, Barcelona, 1966.

31 A. TRAINA, II latino del Pascoli, Firenze, 1971 y Poeti Latini (e Neolatini). Note e saggi filologici, Bologna, 1975, pp. 337 ss. sobre todo.

32 Para el concepto de einheitliche Kultur, de "cultura unitaria", cf. F. LEO, "Die Originalität der römischen Literatur", Festrede in Namen der Georg-Ausgust-Universität zur Akademischen Preisverteilung, Göttingen, 1904, pág. 4 ("Die Geschichte kennt Kein Beispiel einer Kulturwirkung, die ununterbrochener angedauert hätte als die der römischen Litteratur") y F. KLINGNER, Römische Geisteswelt, Wiesbaden, 1952, pp. 13 ss. y 561 ss.; en el mismo sentido puede verse, O. SEEL, "Von Wesen lateinischer Kultur", Weltdichtung Roms zwischen Hellas und Gegenwart, Berlín, 1965, pág. 485. 


\section{NOTAS PARA UN ESTUDIO SISTEMATICO}

otra que la de que tales literaturas -y sus "lenguas especiales" correspondientesconstituyen el objeto de estudio de especialidades más concretas y que, atendidas por especialistas debidamente formados para ello, reclaman, cada vez más, un puesto propio en el ámbito de la investigación, así como unas cátedras universitarias y unos cursos, que contribuyan a su necesaria difusión no sólo entre los filólogos clásicos y los latinistas, sino también $-\mathrm{y}$, de modo especial- entre los romanistas y entre cuantos se interesan por los problemas y cuestiones de Lingüística, de Historia o de Literatura en general;

b) Desde un punto de vista geográfico, la "literatura latina" comprende "das gesamte Schirifttum" 33 latino del período cronológico antes indicado, esto es, el conjunto de obras escritas en latín -desde el s. III a. C. hasta el s. V d. C.-con independencia del lugar de nacimiento o formación del autor. Porque, si bien es cierto que - como observa Leo ${ }^{34}$ - "Es ist die politische Kraft Roms, die für diese Literatur den Namen der römischen festgesetzt hat" y que -como advierte Schanz $z^{35}$ - "fast die gesamte römische Literatur ist in Rom entstanden, und Rom ist noch weit mehr das Zentrum für die lateinische Literatur geworden, als heutzutage Paris das Zentrum der französischen Literatur ist", no menos cierto es que -como indica Büchner ${ }^{36}$ - "Die Sprache der Stadt Rom hat zusammen mit dem imperium sich erst über Italien, dann über die westliche Hälfte des Reiches, aber auch weit gegen Osten hin verbreitet". Esta expansión y difusión del latin ${ }^{37}$ supuso, asimismo, la expansión y difusión de la literatura escrita en dicha lengua. Recuérdese que en el 241 a. C. Sicilia había sido organizada como provincia romana y que en el 238 lo serían Cerdeña y Córcega; en el 197 España; en el 167 el Ilírico; en el 146 Africa; en el 120 la Galia meridional y en el 50 la septentrional; en el 15 la Retia y en el 107 d. C., bajo Trajano, la Dacia; la Galia Cisalpina estaba conquistada desde el 191 a. C. y los vénetos -aunque la constitución de la provincia no se remonta más allá del 81 - se habian sometido al poder romano en el $215^{57}$. La difusión de la lengua y de la cultura romana habia sido, pues, paralela a la Verbreitung (a la expansión) del poderío político y militar de Roma. Así, Italia estaba romanizada desde la guerra de conquistas (91-88 a. C.); "España, desde los comienzos de nuestra cronología, Africa desde el siglo II y las Galias desde finales del siglo III" ${ }^{39}$. Se comprenderá, por tanto, una afirmación

33 Cf. M. SCHANZ, Geschichte der römischen Literatur (= Handbuch der Klassischen Altertumswissenschaft, herausgegeben von I. Müller), VII, I, I, Erster Teil, 1, Hälfte, pág. 1.

34 Cf. F. LEO, Geschichte der römischen,Literatur, Bd. 1, Darmstadt, 1967, pág. 3.

35 Cf. M. SCHANZ, op. cit., pp. 12-13.

36 Cf. K. BUCHNER, Humanistas Romana, pág. 244.

37 Cf. A. BUDINZSKY, Die Ausbreitung der lateinischen Sprache über Italien und die Provinzen des römischen Reiches, Berlín, 1881.

38 Cf. C. TAGLIAVINI, Orígenes de las lenguas neolatinas, México, 1973, pág. 153.

39 Cf. L. BIELER, Historia de la literatura Romana, traducción española de M. SANCHEZ GIL, Madrid, 1968, pág. 10 


\section{JAIME SILES}

como la de Bieler" ${ }^{40}$, para quien "La creación literaria de los hombres nacidos en tales paises pertenece esencialmente a la literatura romana; los romanos nativos de la misma capital apenas si la representan, salvo los oradores: son los nativos del resto de Italia y luego de las Provincias los que nos transmiten lo típicamente romano". De ahi que consideremos, como Literatura Latina tambien, el conjunto de obras escritas en latín, dentro y fuera de Italia, durante el período cronológico antes indicado- por escritores que - latinos o no, romanos o no-se sirvieron, para su expresión, de la lengua literaria de Roma. En consecuencia, los límites geográficos de la "literatura latina" no son otros que los límites geográficos de la expansión del "imperium" y de la conquista romana.

1.3.2. A la titulación de este apartado la denominábamos, de modo acaso excesivamente general, "limites, espacios y cronologia de la literatura latina". No se nos ocultan, sin embargo, los riestos que una titulación (así de general) entraña. De ahi que nos hayamos limitado a fijar y establecer -de acuerdo con un criterio que considerábamos racional y razonado - la delimitación cronológica y geográfica de la literatura latina. Dejamos, pues, sin considerar aquí dos cuestiones que, por su importancia y complejidad, exigen un tratamiento aparte y que examinaremos en los apartados siguientes. Estas cuestiones son -lo adelantamos ya-: 1) la de la cronologia de la literatura latina, de la que nos ocuparemos en el apartado titulado Historia Literaria y 2) la de los espacios intrínsecos de dicha literatura, que no son otra casa que los espacios textuales de la misma, es decir, los géneros literarios, de los que tratamos en el punto 2.2.2.

\section{HISTORIA LITERARIA}

\subsection{Problemática de una Historia de la Literatura Latina.}

Llamamos "Historia Literaria" a aquella parte de la Literaturwissenschaft, que se ocupa, desde un punto de vista extrínseco, del estudio de la configuración diacrónica de la literatura y que pone su érifasis en la distribución, según un orden cronológico, de las etapas sucesivas de la constitución y desarrollo de la mis$\mathrm{ma}^{42}$.

40 Cf. L. BIELER, Op. cit., pág. 10

41 Cf. infra.

42 Cf. G. LANSON, Méthodes de l' histoire littéraire, París, 1925: H. CYSARZ, Literaturgeschichte als Geisteswissenschaft, Halle, 1926; G. GENETTE, "Littérature et histoire" L'Enseignement de la littérature, París, 1971, pp. 243-251; una bibliografia más amplia que la que damos aquí, sobre los problemas de "Literatura e Historia" puede verse en M. PAGNINI Estructura literaria y métodos critico, traducción de C. Mazo del Castillo, Madrid, 1975, pp. 216-217 donde junto con algunos de los autores citados por nosotros, se recogen otros como Barthes, Bateson, Cazamian, Crane, Croce, Getto, Greimas, Guglielmi, Henry, Meinecke, Picard, Popper, Pottle, Praz, Sanders, Spitzer, 


\section{NOTAS PARA UN ESTUDIO SISTEMATICO}

La cuestión que una disciplina así plantea es la de si "es posible escribir historia literaria", esto es, la de si es posible escribir "una cosa que sea al propio tiempo literatura e historia" 43 , porque "la mayoría de las historias de la literatura son historias sociales o historias del pensamiento tal como lo ilustra la literatura, o bien son un conjunto de impresiones o juicios sobre obras determinadas, en orden más o menos cronológico"44 . Se comprenderá, pues, que lo primero que, en este sentido, tenemos que hacer es responder a esa pregunta. Es decir, pronunciarnos sobre la posibilidad o imposibilidad de hacer historia literaria y, más concretamente, historia de la literatura latina. Pues bien, a dicha pregunta puede responderse de dos maneras:

a) afirmativamente, teniendo en cuenta la serie de manuales que ostentan el título de Historia de la Literatura y, en el caso que ahora nos ocupa, el de Historia de la Literatura Latina ${ }^{45}$,

b) negativamente, si consideramos que la historia literaria, en general, y las historias de la literatura latina, en particular, "Constituyen -como indican Warren y Wellek $^{46}$ - un revoltijo de etiquetas políticas, literarias y artísticas que es imposible defender".

La respuesta afirmativa correspondería, pues, a los autores de manuales denominados "Historia de la Literatura" o "Historia de la Literatura X", así como

Teesing, Todorov, etc., la diversidad de cuyas opiniones no hace sino evidenciar la problemática naturaleza del asunto tratado.

Cf. R. WELLEK-A WARREN, op. cit., pág. 303.

Cf. Ibid., p. 303.

45 Cf. las ya citadas de Bieler, Bickel, Leo, Schanz, y las de A. ROSTAGNI, Storia della letteratura latina, Torino, 1964; E. PARATORE, La letteratura latina dell' età repubblicana e augustea y La Letteratura latina dell' età imperiale, Firenze, 1969-1970; J. WIGHT DUFF. A Literary History of Rome, London, 1909-1927 asi como otras más antiguas y más modernas: la de F. A. WOLF, Geschichte der römischen Literatur, Halle, 1787, la de F. SCHOELL, Histoire de la littérature romaine, París, 1815, la de C. LAMARRE, Histoire de la littérature latine, París, 1901-1907, la de Ch. T. CRUTWELL, A History of Roman Literature, London, 1907, la de W. S. TEUFFEL, Geschichte der römischen Literatur, Neue bearbeitet von W. KROLL y F. SKUTSCH, Leipzig, 19131920, la de R. PICHON, Histoire de la littérature latine, París, 1912, la de A. G. AMATUCCI, Storia della letterature romana, Napoli, 1912-1916, la de Th. BIRT, Römische Literaturgeschichte in fünf Stunden gesprochenen, MARBURG, 1919 la de V. USSANI Storia della letteratura latina nell' età republicana e augustea, Milano, 1929, la de A. KLOTZ, Geschichte der römischen Literatur, Bielefeld, 1930, la de A. HAUSRATH, Geschichte der römischen Literatur, Bielefeld, 1930, la de C. MARCHESI, Storia della letteratura latina, Messina, 1932-1933, la de E. NORDEN, Geschichte der lateinischen Literatur, Leipzig, 1933, la de N. TERZAGHI, Storia della letteratura latina da Tiberio a Giustiniano, Milano, 1934, la de E. BIGNONE, Storia della letteratura latina, Firenze, 1947 , la de O. TESCARI, Storia della letteratura romana, Torino, 1941, la de K. BUCHNER, Römische Literaturgeschichte, Ihre Grundzüge in interpretierender Darstellung, Stuttgart, 1962, etc. 


\section{JAIME SILES}

a los estudiosos, profesores o especialistas que - como Vanucci ${ }^{47}$, Funaioli $^{48}$, o Büchner ${ }^{49}$ - consideran como E. Greenlaw ${ }^{50}$ - que la labor del estudioso de la literatura consiste en estudiarla "a la luz de su posible contribución a la historia de la cultura". La respuesta negativa sería, en cambio, la suscrita por quienes -como Wellek y Warren" ${ }^{51}$ - consideran: 1) que "la historia literaria no debería contentarse con aceptar un esquema trazado a base de materiales diversos con fines diferentes "in mente"; 2) que "la literatura no debe entenderse como simple reflejo pasivo o copia servil del desenvolvimiento político, social o aún intelectual de la humanidad", 3) que "el período literario debe fijarse mediante criterios puramente literarios".

En realidad, estos dos tipos de respuesta - que aquí se nos presentan enfrentados-corresponden a la oposición existente entre dos puntos de vista: uno, el que considera a la obra literaria -y, por tanto, a la literatura-como "un signo en el sistema de signos literarios, culturales, sociales de una determinada época o situación" 52 ; otro, el que considera que "los valores se hallan en las estructuras, y el estudio de las estructuras es el estudio de los valores, y estudiar las estructuras significa hacerse sensible a los valores"53 y que, por lo tanto, deben ser excluídos "aquellos procedimientos de investigación que subordinan su interés por la literatura a un interés algo distinto de ella"54. Sin embargo, la respuesta adecuada -o, al menos, la que así nos lo parece- no consiste en negar o afirmar la posibilidad de hacer historia literaria en general e historia de la latina en particular, sino en criticar, racionalmente, la forma en que las historias literarias -y las historias de la literatura latina - han sido hechas, los presupuestos en que se han basado y la orientación u orientaciones dadas a las mismas. De ese modo, sustituimos, $-\mathrm{y}$ no se nos oculta - el problema de "la posibilidad o no de hacer historia literaria" ( = historia de la literatura latina) por el problema de si tales historias responden a criterios válidos, de si se apoyan en principios sólidos y de si constituyen una forma válida de ordenación histórica de la literatura. Lo que equivale a:

1) Presuponer que sí que puede hacerse historia de la literatura (latina);

47 Cf. A. VANUCCI, Studi storici e morali intorno alla letteratura latina, Torino, 1886.

48 Cf. G. FUNAIOLI, "Disegno storico della letteratura romana", Studi di letteratura antica..., I, pp. 35-120.

49 Cf. K. BUCHNER, "Römischen Geschichte und Geschichte der römischen Literatur", Aufstieg und Niedergang . .., Bd. II, 2, pp. 759-780.

50 Cf. E. GREENLAW, The Province of Literary History, Baltimore, 1931, pág. 174, citado por WELLEK-WARREN, op. cit., pág. 24.

51 Cf. op. cit., 318.

52 Cf. supra, 1.3.1.

53 Cf. M. PAGNINI, op. cit., pág. 127.

54 Cf. W. SHUMAKER, Elementos de Teoria Crítica, traducción de M. FERNANDEZ MONTES, Madrid, 1974, pág. 25. 


\section{NOTAS PARA UN ESTUDIO SISTEMATICO}

2) Considerar si la forma en que la historia de la literatura (latina) se ha hecho, las orientaciones que se le han dado y los presupuestos de que se ha partido, son susceptibles de crítica, de perfeccionamiento o de modificación, y

3) Determinar cúales son, en consecuencia, los criterios que estimamos válidos para hacer historia literaria, en general, e historia de la literatura latina, en particular.

Las razones de una respuesta estructurada en forma tripartita son, en el caso de una historia literaria general y en el de una historia de la literatura latina en particular, las siguientes;

- A) Para el primer punto:

1) Que "por haber confundido durante largo tiempo su objeto con el de disciplinas vecinas, la historia literaria, la rama más antigua entre las disciplinas de estudios literarios, hace hoy las veces de pariente pobre"55. Más no, por ello, puede afirmarse la imposibilidad de hacer una auténtica historia literaria y una historia de la literatura latina, concebidas no como una forma de investigación y explicạción de la literatura, sino, más bien, como una ordenación histórica de la misma;

2) que, además, hay estudiosos, como Etiemble ${ }^{56}$, para quienes "la historia literaria y la filología siguen siendo los dos pilares de la crítica", y teóricos como Schumaker ${ }^{57}$, para quienes "es casi imposible (. . .) separar la crítica literaria de la historia de la literatura en alguna de sus formas", porque "la base de distinción sería el fuerte énfasis que la historia de la literatura pone sobre las interconexiones, la suceción y la casualidad" "gran parte de la historia de la literatura insinúa juicios de labor". y "gran parte de la mejor crítica está impregnada de historia". De lo que "se deduce que no sólo puede hacerse historia literaria e historia de la literatura" (latina), sino que además debe hacerse porque dicha "historia" está íntimamente unida a la crítica literaria y constituye, como decía Etiemble, uno de los pilares en que ésta se apoya;

3) que, como indica Claude Levi-Strauss ${ }^{58}$, "la historia es indispensable para inventariar la totalidad de los elementos de cualquier estructura humana o no humana. La historia, donde quiera que exista, no puede ser ignorada porque, de una parte multiplica, a lo largo de la dimensión temporal, la cantidad de los niveles sincrónicos disponibles, y de otra, precisamente

55 Cf. O. DUCROT-T. TODOROV, Diccionario Enciclopédico de las Ciencias del Lenguaje, traducción de E. PEZZONI, Buenos Aires, 1975, pág. 177.

56 Cf. ETIEMBLE, Ensayos de Literatura (verdaderamente) general, versión española de R. YAHNI, Madrid, 1977, pág. 159.

57 Cf.op. cit. pág. 25.

58 Tomo la cita de A. DOMINGUEZ HIDALGO, Iniciación a las estructuras literarias, México, 1977, pág. 224. 


\section{JAIME SILES}

por el hecho de haber transcurrido los niveles pasados se ven libres de las ilusiones de la subjetividad y pueden servir para controlar las inexactitudes de la percepción intuitiva y las ilusiones de una seducción recíproca que, aunque atractiva, corre siempre el riesgo de generar una complicidad en detrimento de la veracidad". De ahí, precisamente la necesidad cient $i$ fica de una ordenación histórica de la literatura y de ahí, también, la necesidad docente de disponer de una ordenación que, como la histórica, permite establecer los ejes, los límites, la evolución y la cronología de una literatura;

- B) Para el segundo punto:

1) Que las historias literarias han partido:

a), en el caso de la historia literaria en general, o bien de "modelos organicistas ", como el de la "planta" ("Aristóteles, habla de la madurez de la tragedia; Friedrich Schlegel describe cómo la poesía griega, creció, proliferó, floreció, maduró, se seco y se convirtió en polvo;Brunetière habla de la adolescencia, de la madurez y de la vejez de la tragedia francesa") ${ }^{59}$; o bien del llamado "modelo del caleidoscopio", frecuente en los estudios literarios del siglo XX, donde la representan Shklovski (para quien el "trabajo de las escuelas literarias consiste mucho mås en la disposición de las imágenes que en su creación") T.S. Eliot (para quien "la originalidad poética es en gran parte una manera original de reunir los materiales más dispares y desemejantes para hacer con ellos una totalidad nueva") y Northrop Frye, (para quien "todo lo que es nuevo en literatura es reelaboración de lo viejo"); o bien de lo que Todorov llama el modelo del día y de la noche, cuyo prototipo es la fórmula hegeliana tesis-antítesis-síntesis (en este modelo "los cambios se perciben como movimientos de oposición entre la literatura de ayer y la de hoy") ${ }^{60}$; dentro de él, puede considerarse incluído lo que, desde el Antiguo Testamento, Herodoto, Hecateo de Mileto $^{61}$, hasta Ortega y Julián Marías ${ }^{62}$, pasando por Comte, Cournot, Dromel, Ferrari, Lorenz, Mill, Rümelin, Soulavie, Mentré, Dilthey, Pinder y Peterson, se denomina "teoría de las generaciones" ${ }^{63}$. Y b), en el caso de las historias de la literatura latina: casi siempre de criterios de periodización, basados en: 1) tendencias estéticas o en el nombre de un político o en el de un determinado escritor (es la forma en que lo ha hecho Bayet en su Littérature Latine); 2) generaciones (es la forma en

61 Cf. F. A. KEHRER, Der Wandel der Generationen, eine Biologisch-Soziologische Studie Stuttgart, 1959, pp. 6-19. (citado por N. JANSEN, La teoría de las Generaciones y el cambio social, traducción de J.L. LOPEZ MUÑOZ, Madrid, 1977, pág. 17 ss.).

62 J. MARIAS, El método histórico de las generaciones, Madrid, 1967. 


\section{NOTAS PARA UN ESTUDIO SISTEMATICO}

que lo han hecho Paladini y Castorina $\left.{ }^{64}\right)$; 3) relaciones entre historia política e historia cultural de Roma (Paratore); 4) etapas coincidentes no con la evolución de la literatura latina, sino con periodos definidos de la constitución política romana (Schanz, Rostagni);5) juicios de valor y delimitaciones como "Edad de Oro", "Edad de Plata", etc., que varían de un tratadista a otro $^{65}$;

2) Que, de lo antedicho, se deduce: a) que dichas historias de la literatura latina han sido hechas con criterios extrinsecos; b) que sus orientaciones han sido, sobre todo didácticas y cronologizadoras; c) que los periodos literarios han sido definidos y fijados atendiendo a razones extraliterarias y d) que, en cada una de ellas, la parte mejor tratada es, precisamente, aquella que el estudioso, autor de dicha "literatura" mejor conoce (lo que no hace, sino quitar valor al conjunto de la obra. ya que, en ella, hay partes que se resienten y otras que se acrecientan). De modo que nos vemos obligados a exponer los criterios que consideramas válidos para hahacer historia literaria en general e historia literaria latina en particular. Lo que equivale a dar las razones existentes:

- C) Para el tercer punto:

1) Que, "el objeto específico de la historia literaria es (la) variabilidad de la literatura, y no la génesis de las obras, que algunos siguen considerando el objeto de la historia literaria y que, para nosotros, pertenece al ámbito de la psicología o la sociología de la creación"66;

2) Que hay que distinguir entre historia de la literatura e historia social o política o constitucional, porque "reemplazar la una por la otra es afirmar que puede explicarse la variabilidad literaria por los cambios de la sociedad: la respuesta está dada ya antes de que pueda formularse la pregunta. Lo cual no significa que ambas series sean independientes: distinguir no significa aislar; se trata más bien de establecer un orden jerárquico en el obieto de estudio, orden que se refleja necesariamente en la forma misma del estudio"67;

3) Que "la historia literaria tampoco coincide con el estudio inmanente ("llámese lectura o descripción) que procura reconstruir el sistema del texto. Este último tipo de estudic -que puede abarcar el sistema de todo un período literario- aborda su objeto "sincrónicamente" por así decirlo. La historia debe considerar el paso de un sistema a otro, es decir, debe em-

64 Cf. también, T. GONZALEZ-ROLAN, "Ordenación de la historia de la literatura latina", Estudios Clásicos, 17 (1973), pp. 241-260.

65 Compárese la delimitación que, a la "Edad de plata", dan Schanz y Hosius con la que, por ejemplo, da Wight Duff y se comprenderá lo que decimos.

Cf. DUCROT-TODOROV, op. cit., pág. 173. 


\section{JAIME SILES}

plear un enfoque diacrónico"68, porque -como observa Tinianov- "la noción fundamental de la historia literaria es la del reemplazo de sistemas". De ahí que el periodo literario puede definirse como "el tiempo durante el cual un determinado sistema se mantiene sin cambio"

4) Oue "la historia literaria debe estudiar el discurso literario y no las obras" porque "éstas sólo son afectadas por el tiempo en la medida en que son objeto de interpretaciones diferentes" y esto "se relaciona más bien con la historia de las ideologías". De donde se deduce que la historia literaria "se define como parte de la poética"70; y

5) Que, en consecuencia con el punto anterior, la pregunta que el historiador de la literatura debe formularse es la que de iqué es lo que cambia en el interior del discurso literario ${ }^{71}$.

Todo lo cual, aplicado al caso de una posible Historia de la Literatura Latina, nos lleva a establecer una serie de presupuestos generales que son:

1) Que, como indica Todorov ${ }^{72}$ la oposición entre estructura e historia es ficticia y que "sólo al nivel de las estructuras se puede describir la evolución literaria" 73 , ya que -también aquí- sincronía y diacronía tienen que ser entendidas como perspectivas profundamente complementarias ${ }^{74}$,

2) Que "precisando los estilos de época en períodos literarios (área espaciotemporal en que determinado sistema de signos desarrolla y agota posibilidades de significación)" se podrá elaborar una auténtica historia literaria que sea "una diacronía de las estructuras sincrónicas producidas en el contexto social" 75 ;

3) Que una historia literaria, así concebida, no puede ser obra de un sólo autor, sino de una serie de especialistas que, desde ángulos distirtos, considere - cada uno desde su especialidad y su visión - la diacronía de dichas

Cf. DUCROT-TODOROV, op. cit., pág. 173.

69

Ibid., pág. 175.

70 Cf. DUCROT-TODOROV, op. cit., pág. 173.

71 Ibid.. pág. 174.

72 Cf. A. DOMINGUEZ HIDALGO, op. cit. pág. 225.

73 Cf. además de R. DH. FUSCO. Storia こ̌ struttura, Nápoli, 1970.

74 Hago aquí uso extensivo a la literatura de las indicaciones hechas en lingüística por A. SOMMERFELT, ("Points de vue diachronique, synchronique et panchronique en linguistique générale", Norsk Tidsskrift for Sprogvidenskap. 9 (1938), pp. 240-249 y Diachronic and Synchronic Aspects of Language, The Hague, 1962), E. BUYSSENS, ("Origine de la linguistique synchronique de Saussure", Cahiers $F$, de Saussure, 18 (1961), pp. 17-33). B. Malmberg, "Synchronie et diachronie", comunicación al Xe Congrès International de linguistes (28 août - 2 septembre 1967), Bucarest, 1967) y, sobre todo, por E. Coseriu, (Sincronía, Diacronia e Historia. El prohlema del cambio lingüistico, Madrid, 1973, págs, 273 ss. sobre todo).

75 Cf. A. Dominguez Hidalgo, op. cit., pág. 224. 


\section{NOTAS PARA UN ESTUDIO SISTEMATICO}

estructuras sincrónicas ${ }^{76}$.

Así las cosas, se comprenderá que el historiador de la literatura latina deba, para responder a la pregunta "¿qué es lo que cambia en el interior del discurso literario?", considerar previamente:

1) que las estructuras sincrónicas de la literatura latina y el discurso literario latino -considerados intrínsecamente-dependen de un sistema (la $\mathrm{Re}$ tórica), que, a su vez, corresponde a una Weltanschauung y que determina la morfologia (los géneros literarios) de dichas estructuras; $y$

2) que, por lo tanto, la diacronía de dichas estructuras sincrónicas no es otra cosa que el cambio y modificación internos, operados dentro de la morfología de dichas estructuras, como consecuencia de la propia evolución de los géneros, que son receptores y recipendarios del cambio histórico y de su consiguiente evolución. Porque "las obras no se transforman, no son más que los signos de las transformaciones. Tampoco los géneros se transforman: son los productos de las transformaciones, de las trans-formas" y "lo que cambia tiene una naturaleza aún más abstracta, y se sitúa de algún modo "detrás". o "más alláa" de los géneros"77.

De donde se deduce que la tarea de realizar una Historia de la Literatura Latina conlleva consigo $-\mathrm{y}$ presupone- la tarea de: por un lado, determinar y precisar, previamente, la morfologia de las estructuras sincrónicas en que dicha literatura funciona y se realiza, $\mathrm{v}$, por otro, la de considerar los modos y las formas en que se producen la evolución y el cambio de las mismas. De este modo la Historia de la Literatura Latina queda circunscrita no sólo a una ordenación cronológica de autores y de obras - que es lo que los manuales nos dan-, sino a estudiar la variabilidad formal, que, para Tianianov, consiste en la redistribución de las formas y de las funciones. Porque "la forma cambia de función" y "la función cambia de forma" y "el dinamismo - según Vinogradov ${ }^{78}$ - debe presentarse o bien como el reemplazo de un sistema por otro, o bien como una transformación parcial de un sistema único cuyas funciones centrales permanecen relativamente estables". Este es el caso - nos parece- de la Historia de la Literatura Latina. Y, en consecuencia, el estudio de dicha transformación tendrá que hacerse teniendo en cuenta lo que dice Tomasevskij" : que "cada época literaria, cada escuela está caracterizada por un sistema de procedimientos que le es propio y que representa el estilo (en el sentido amplio) del género o de la corriente literaria". Pero, sin olvidar tampoco, que ese "sistema" de época, de escuela o de co-

76 Un ejemplo de ello puede ser la Römische Literatur editada bajo la dirección de M. Fuhrmann (Darmstadt, 1974) en ei tomo III del Neues Handbuch der Literaturwissenschaft.

77 Cf. DUCROT-TODOROV, op. cit., pág. 174.

78 Cf. DUCROT-TODOROV, op. cit., pág. 175.

79 Citado por DUCROT-TODORV, op. cit., pág. 174. 


\section{JAIME SILES}

rriente literaria - aunque es un sistema en si-constituye, dentro del Sistema ${ }^{80}$, que la literatura latina es, sólo un subsistema, es decir, una forma -particularde realización. De ahi, precisamente, la necesidad de partir-a la hora de intentar hacer una Historia de la Literatura Latina, que de verdad lo sea-de las estructuras sincrónicas que informán el sistema de la misma ${ }^{81}$ y del dinamismo diacrónico que dichas estructuras experimentan a lo largo de su evolución. Sólo así, creemos, puede hacerse Historia de la Literatura, en general, e Historia de la Literatura Latina, en particular. De lo que se trata, pues, es de estudiar:

\section{1) el Sistema literario latino;}

v 2) la variabilidad formal y el dinamismo, que a lo largo de su historia, dicho Sistema experimenta.

Hasta ahora, y preocupados por determinar cuáles eran los criterios válidos para hacer una auténtica Historia de la literatura latina, la atención de nuestro discurso se ha centrado, principalmente, en la consideración de la complejidad y problemática relativos al segundo punto, es decir, a la variabilidad formal y al dinamismo, que son, por así decirlo, el objeto fundamental de una historia literaria. Pero, como dicha variabilidad y dicho dinamismo sólo se entiende por relación a -y como evolución-del Sistema literario latino, debemos, previamente, determinar lo que ese Sistema es, así como el coniunto de realizaciones sincrónicodiacrónicas que el mismo presenta. De ese modo lograremos una auténtica Historia de la Literatura Latina, que sea: por un lado, descripción y análisis de dicho Sistema y, por otro, descripción y análisis de la variabilidad formal, del dinamismo y de la evolución de dicho Sistema. En las líneas precedentes, acabamos de ver cuáles eran los criterios que nos parecen válidos para describir y analizar la variabilidad formal, el dinamismo y la evolución del Sistema literario latino y que constituyen el obieto, propiamente dicho, de la Historia Literaria -en general-y de la Historia de la Literatura Latina - en particular-. Pues bien, en las líneas que siguen nos ocuparemos de los rasgos morfológicos y de las estructuras que determinan eso que llamamos el Sistema Literario Latino.

\section{2. La Retórica, los Géneros Literarios y la Morfología de la Literatura Latina: Consideración General:}

Bajo este rótulo, tan amplio como general, pretendemos establecer - a modo

80 Cf. C. GULLLEN, Literature as System, Princeton University, 1971.

81 Hago aplicación aquí de algunos de los principios expuestos por E. Coseriu (cf., en especial, "Coordinación latina y coordinación románica", Actas del III Congreso Español de Estudios Clásicos, 3 (Madrid, 1968), pág. 38, donde el linguista rumano llama la atención sobre un punto de vista que compartimos por entero, el de que "la pregunta estructural por excelencia (. . .) es la pregunta por los rasgos distintivos, al mismo tiempo constitutivos y definitorios, de sus unidades funcionales".), que, creemos, pueden extenderse, también, al estudio de las unidades literarias. 


\section{NOTAS PARA UN ESTUDIO SISTEMATICO}

de notas- los rasgos morfológicos y las estructuras que -creemos-determinan y constituyen el Sistema Literario Latino. Nuestras consideraciones sobre el mismo no pueden ser, por otra parte (esto no es una exposición de principios teóricos, ni tampoco una elaboración de lo que podríamos denominar "Grundlagen de la literatura latina"), sino un intento de ordenación sincrónico-diacrónica de dicho Sistema, que es el modo - nos parece-, en que debe hacerse una Literatura Latina que sea, de verdad, una Historia de la misma. Es decir, una -como se ha dicho 82 - "diacronía de estructuras sincrónicas". Pues bien, para ello -y ya que hemos dedicado el apartado anterior a discutir los problemas que un planteamiento, así concebido, entraña- procederemos a describir y a, brevemente, analizar lo que consideramos puntos de partida obligatorios y que son, en el caso de una literatura como la latina, dos: la Retórica y los Géneros Literarios, de los cuales depende tanto la base teorética como la morfología de esas estructuras sincrónicas, que la Historia Literaria - desde un punto de vista diacrónico- se propone estudiar.

\subsubsection{La Retórica:}

La Retórica no es - como tantas veces se cree y tantas veces se ha creido- la simple enumeración de las figuras o la clasificación y la rotulación de la elocutio. No. la Retórica es, en la antigüedad sobre todo, algo más que eso ${ }^{83}$, ya que, por las bases filosóficas en que se apoya, constituye una Weltanschauung a todos los niveles y en todos los sentidos: filosófico ${ }^{84}$, estético ${ }^{85}$, lingüístico ${ }^{86}$, jurídico ${ }^{87}$, político $^{88}$, literario ${ }^{89}$. De todos estos órdenes los que aquí más nos intere-

82 Cf. supra 2.1 .

83 Cf. R. VOLKMANN, Hermagoras oder Elemente der Rhetorik, Stettin, 1865 y Die Rhetorik der Griechen und Römer im systematischer Ubersicht dargestellt, Leipzig, 1885 (NDr. 1963); A. E. CHAIGNET, La Rhétorique et son histoire, París, 1888; O. NAVARRE, Essai sur la rhétorique grecque avant Aristote, París, 1900; W. KROLL, RE, Suppl. VII 1039-1138 (1940), s.v. "Rhetorik"; C.S. BALDWIN, Ancient Rhetoric and Poetic, Gloucester, 1959; H. LAUSBERG, Handbuch der literarischen Rhetorik, 2 Bde. München, 1960; A. PLEBE, Breve storia della retorica antica. Milano, 1961; H. SCHOPDAU, Antike Vorstellungen von der griechischen Rhetorik, Diss. Saarbrucken, 1969; A. KIBEDI VARGA, "Rhétorique et Littérature", Communications, 16 (1970), pp. 172-229; W. EISENHUT, Einführung in die antike Rhetorik und ihre Geschichte, Darmstadt, 1974; J. MARTIN, Antike Rhetorik. Technik und Methode, München, 1974.

84 Cf. A. MICHEL, Rhétorique et philosophie chez Cicéron, París, 1960.

85 Cf. A. MICHEL, "Rhétorique, philosophie et esthétique", REL, 51 (1973), pp. 302325.

86 Cf. K. BARWICK, Probleme der stoischen Sprachlehere und Rhetorik, Berlín, 1957.

87 Cf. J. STROUX, Römische Rechtswissenschaft und Rhetorik, Postdam, 1940; G. NEUMEISTER, Grundsätze der forensischen Rhetorik. München, 1964.

88 Cf. G. KENEDY, The Art of Persuassion in Greece, Princeton, N.Y. 1963. 


\section{JAIME SILES}

sa son, como es obvio, el lingüistico, el estético y el literario. Pero conviene subrayar que la Retórica no se agota ni termina con ellos, sino que amplia el campo de su extensión y el círculo de sus implicaciones a otros muchos niveles de la realidad. De ahí precisamente, la importancia que los antigüos le concedían y que se manifiesta tanto en el papel que, como disciplina, ocupaba en su sistema de educación $^{90}$ como en la concepción ciceroniana del orator ${ }^{91}$.

La Retórica, si por algo nos interesa, es, precisamente, porque, por el hecho de constituir -como se ha dicho-- una W'eltanschauung en muy diversos órdenes, viene a ser -por su incidencia en el orden lingïstico, en el orden estético y en el orden literario- un auténtico Sistema de critica literaria ${ }^{92}$ que, debido-sobre todo- a su intencionalidad eminentemente práctica y política, puso su énfasis en el estudio del lenguaje no como lengua, sino como discurso. Este es, fundamentalmente, el interés que la Retórica reviste: que constituye, por así decirlo, el Sistema de critica literaria de la .Antigüedad ${ }^{93}$ y no sólo de ella. También, de la Edad Media ${ }^{94}$, del Renacimiento ${ }^{95}$, del Barroco $^{96}$, del Neoclasicismo ${ }^{97}$ c incluso de nuestros dias, en los que si interpretamos bien movimientos como los del formalismo ruso ${ }^{98}$, el "New Criticism" americano" ${ }^{99}$, el Círculo de Praga

89 Cf. W. R. ROBERTS, Greek Rhetoric and literary Criticism, New York, $1928(=1963)$.

90 Cf. E. JULLIEN, Les professeurs de littérature dans l' ancienne Rome et leur enseignement depuis l'origine jusqu'à la mort d'Auguste, París, 1885; M. LECHER, Érziehung und Bildung in der griechischömischen Antike, München, 1933, P. BOYANCE; "La rhétorique dans l' humanisme latin", L' Information Litteraire, 1950, pp. 19-24; H.I. MARROU, Histoire de l'education dans l' Antiquité, París, 1955; M.L. CLARKE, Rhetoric at Rome, New York, 1963; G. KENEDY, The Art of Rhetoric in the Roman World, Princenton, 1972.

91 Cf. H.K. SCHULTE, Orator. Untersuchungen über das ciceroniasche Bildungsideal, Frankfurt, 1935; K. BARWICK, Das rednerische Bildungsideal Ciceros, Abh. d.Sächs. Akad. d. Wiss. zu Leipzig, 1963.

92 Cf. P. BRUNEL, D. MADELENAT, J-M. CLIKSOHN y D. COUTY, La Critique Littéraire, París, 1977, pp. 9 y ss.

93 Cf. C. BIONE, I piú antichi trattati d'arte retorica in lingua latina, Pisa, 1910, (Roma, 1965); B. RIPOSATI, "Problemi di retorica antica", Introduzione alla Filologia Classi$c a$, pp. 657-789.

94 Cf. Las obras citadas de AUERBACH y CURTIUS y H. CAPLAN, Of Eloquence. Studies in Ancient and Mediaeval Rhetoric, Ithaca and London, 1970.

95 Cf. C. S. BALDWIN, Renaissance Literary Theory and Practice, New York, 1939; A. GARCIA BERRIO, Formación de la teoria literaria moderna. La Tópica Horaciana en Europa, Madrid, 1977.

96 Cf. J. SILES, El Barroco en la poesia española, Màdrid, 1976, p. 71 y ss.

97 Cf. WELLEK-WARREN, op. cit., pp. 271 ss.

98 Cf. V. ERLICH, El formalismo ruso, traducción de J. CABAÑES, Barcelona, 1974; A. GARCIA BERRIO, Significado actual del Formalismo Ruso, Barcelona, 1973.

99 Cf.DE AGUIAR e SILVA, op. cit., pp. 413-433; K.D. UITTU, Teoría Literaria y Lingüistica, traducción de R. SARMIENTO GONZALEZ, Madrid, 1975, pp. 133-147. 


\section{NOTAS PARA UN ESTUDIO SISTEMATICO}

-sobre todo, la tesis relativa a la lengua poética y literaria ${ }^{100}$ la estilística -desde Bally, Marouzeau, Cressot, Spitzer y Guiraud hasta Rifaterre ${ }^{101}$ - y el estructuralismo francés de Barthes y el grupo de Tel Quel ${ }^{102}$ se advierte una clara vuelta - a menudo teñida de ignorancia y muchas veces disfrazada de "reinvención"hacia la Retórica Clásica, que el Romanticismo y "el predominio del espíritu historicista"103 del siglo XIX habían hecho desaparecer del ámbito de los estudios literarios.

La revalorización actual que, de la Retórica Clásica, han hecho la estilística, el análisis del discurso y la lingüistica ${ }^{104}$ se explica, sobre todo, por el hecho de que la Retórica Antigüa ponía su acento "en la inventio y la dispositio, es decir, en el contenido y la estructura sintagmática del discurso" 105 y, por eso, precisamente, venía a convertirse en lo que los alemanes llaman Wortkunst y los rusos slovesnost y que, como ellos, constituye $\mathrm{e}^{106}$ una forma más exacta y amplia que la designada por el término "literatura", el cual, por su dependencia de littera, queda de hecho circunscrito sólo a la literatura escrita, con exclusión de la "literatura oral".

La Retórica, en fin, por haber centrado su atención "en el contenido y la estructura sintagmática del discurso", en la inventio y en la dispositio, constituye -y, como tal, debe ser considerada- el Sistema de Critica Literaria de la Antigüedad. Y, por eso (porque la Retórica constituye el Sistema de Crítica Literaria de la Antigüedad, es decir, el coniunto de arquetipos y paradigmas que sirven de referencia a la obra literaria ${ }^{107}$ ) el estudio sincrónico-diacrónico de la Literatura Latina no puede hacerse sin tener en cuenta ese eje paradigmático y referencial, del que las obras reciben su estructura. De ahí el que consideremos la Retórica como uno de los puntos de partida obligatorios - y necesarios-para conocer, comprender e interpretar, correcta y completamente, las formas de las estructura sincrónicas que constituyen el Sistema Literario Latino ${ }^{108}$. Más aún: el estudio de la Retórica Clásica es, para quienes observamos la Literatura Latina, el

100 Cf. El círculo de Praga, Madrid, 1970, pp. 33 ss.

101 Cf. M. RIFATERRE, Essais de stylistique structurale, París, 1971.

102 Cf. R. BARTHES, Ensayos Criticos, pp. 301-307.

103 DUCROT-TODOROV, op. cit., pág. 93.

104 Cf. C. REIS, Técnicas de Análise Textual, Coimbra, 1976.

105 Cf. G. GENETTE, "La Rhétorique des figures". Introducción a P. FONTANIER, Les Figures du Discours, París, 1977, pág. 7

106 Cf. R. WELLEK-A. WARREN, op. cit., pág. 27.

107 Cf. K. BARWICK, Martial und die zeitgenössische Rhetorik, Berichte über die Verhandlungen der sächsischen Akademie der Wissenschaften zu Leipzig, Philologische-historische Klasse, Bd. 104, Heft 1, Berlín, 1959.

108 De utilidad a este respecto es la obra de J. C. Th ERNESTI, Lexicon technologiae Latinorum rhetoricae, Leipzig, $1797(=1962)$. 
modo mejor de penetrar en ella porque, al ser el Sistema de Critica Literaria de la Antiguedad, nos permite, más y mejor que cualquier otro método de crítica, conocer y comprender la literatura antigüa intrinsecamente, es decir, desde ella misma y desde los arquetipos, de acuerdo con los cuales se compuso y se escribió.

\subsubsection{Los Géneros Literarios y la Morfología de la Literatura Latina:}

Si la Retórica constituye - como veíamos- el soporte teorético-conceptual y el Sistema de Crítica Literaria de la Antigüedad (clásica), los Géneros Literarios constituyen las estructuras paradigmáticas en que las literaturas clásicas funcionan y se realizan. Retórica y Géneros Literarios son, pues, los elementos determinantes y constitutivos, respectivamente- del Sistema Literario de la Antigüedad y, por lo tanto, también, del Sistema literario latino, que es el que aquí nos proponemos estudiar. Entre la Retórica y los Géneros Literarios se establecen, además, una serie de relaciones (el intenso proceso de retorización sufrido por la literatura latina -sobre todo, a partir de la época de Augusto- es un ejemplo de ello) que el estudioso de la Literatura Latina no puede ni debe ignorar. De ahi que consideremos, como puntos de partida absolutamente obligatorios y necesarios para acometer el estudio de la Literatura Latina, la comprensión y el conocimiento de los tres ejes fundamentales que, a nuestro juicio, la condicionan, la constituyen y la informan y que son -como ya ha sido indicado $^{109}$ : a) La Retórica, b) Los Géneros Literarios y c) La Morfología de estos últimos.

La Retórica, precisamente por haber puesto su acento "en el contenido y la estructura sintagmática del discurso" (en la inventio y en la dispositio), había contribuído a fijar y establecer las normas y principios de la Schriftsprache y de la Literatur-sprache ${ }^{-110} \mathrm{Y}$, al mismo tiempo, por esa naturaleza y condición de Weltanschauung, que -dijimos- tenía, y, por la serie de implicaciones - de toda índole- de ella derivados, ha contribuído a polarizar y orientar los géneros en una dirección, íntimamente unida y acomodada a sus tres fines: docere, delectare, movere. Hecho éste, más que manifiesto, en el caso de la literatura latina, donde los géneros literarios se ven, en su mayoría, afectados por el influjo total de la Retórica.

109 Cf. supra 2.2.

$110 \mathrm{Cf}$. W. KROLL, "Die Entwicklung der lateinischen Schriftsprache", Glotta, XXII (1933), pp. I ss.; J. Marouzeau, "Pour mieux comprendre les textes latines", Revue de Philologie, XLV (1921), pp. 149 ss. y Quelques Aspects de la Formation du latin littćraire, Paris, 1949; J. Tronskij, "La formazione della lingua letteraria latina", apud F. STOLZ-A.DEBRUNNER-W.P. SCHMID, Storia della lingua latina, Bologna, 1970, pp. 145-194; L. PALMER, "El desarrollo de la lengua literaria", Introduccion al latín, Barcelona 1974, pp. 102-151. 


\section{NOTAS PARA UN ESTUDIO SISTEMATICO}

La cuestión de los géneros, aunque íntimamente unida a $-\mathrm{y}$ determinada por- los fines y presupuestos de la Retórica en la Antigüedad, presenta, en cambio, hoy una problemática muy particular y singularizada, que ha sido objeto, en este siglo, de polémica frecuente y de continua discusión. Los trabajos realizados en este sentido por Müller ${ }^{111}$, Vietor ${ }^{112}$, Van Tieghem ${ }^{113}$, Kohier ${ }^{114}$, Behrens $^{115}$, Donohaue ${ }^{116}$, Pommier ${ }^{117}$, Lämmert ${ }^{118}$, Ruttkowski ${ }^{119}$, Jauss ${ }^{120}$, To$\operatorname{dorov}^{121}$ y otros ${ }^{122}$, así como, por una parte, la dedicación - prácticamente exclusiva-que, a este problema, vienen prestando la revista polaca Zagadnenia rodzajow literackien (en francés, inglés y alemán) y la norteamericana Genre, y, por otra, los estudios de Pearson ${ }^{123}$, Staiger ${ }^{124}$, Hernandi ${ }^{125}$ y Jakobson ${ }^{126}$, constituyen una prueba evidente del interés suscitado, entre los estudiosos y críticos contemporáneos, por una cuestión, tan compleja, como la de los géneros. La serie de posibilidades $-\mathrm{y}$ de dificultades - que, para el estudio de la literatura, dicha cuestión reviste, fue vislumbrada ya por Brunetière ${ }^{127} \mathrm{y}$, con posteridad

111 G. MÜLLER, "Bemerkungen zur Gattungspoetik", Philosophischer Anzeiger, 1929, pp. 129 ss.

112 K. VIETOR, "Probleme der literarischen Cattungsgeschichte", Deustsche Vierteljahrschrift für Literaturwissenschaft und Geistewissenschaft, 9 (1931), pp. 425-447.

113 P. van TIEGHEM, “La question des genres littéraires”, Hélicon, 1 (1938), pp. 95-101.

114 P. KOHLER, "Contribution à une philosophie des genres", Helicon, 1 (1938), pp. 233-244 y 2 (1940), pp. 135-147.

115 I. BEHRENS, Die Lehre von der Eirleitung der Dichtkunst (Beihefte zur Zeitschrift für romanische Philologie, 92), Halle, 1940.

116 J.J. DONOHAUE, The Theory of Literary Kinds: I. Ancient Classifications of Literature; II. The Ancient Classes of Poetry, Dulbuque-Iowa, 1943-1949.

117 J. POMMIER, "L'idée de genre", Publications de l'Ecole normale supérieure. Section des Lettres, 2 (1945), pp. 47-81.

118 E. LÄMMERT, Bauformen des Erzählens, Stuttgart, 1955, pp. 9-18.

119 W.V. RUTTKOWSKI, Die literarischen Gattungen, Bern, 1968.

120 H.R. JAUSS, "Littérature médiévale et théorie des genres", Poétique, I (1970), pp. 79-101.

121 T. DOROROV, Introduction à la littérature fantastique, Paris, 1970, pp. 7-27.

122 Cf. F. LAZARO CARRETER, "Sobre el género literario", Estudios de Poética (La Obra en si), Madrid, 1976, pp. 113-120.

123 N.H. PEARSON, "Literary Forms and Types", The Engiish Institute Annual, 1940 (New York, 1941), pp.61-72.

124 E. STAIGER, Grundbegriffe der Poetik, Zürich-Freiburg, 1968, traducción española: Conceptos Fundamentales de poética, Madrid, 1966.

125 P. HERNANDI, Beyond Genre. New Directions in Literary Classification, Cornell University Press, 1972.

126 R. JAKOBSON, Questions de poétique, Paris, 1973.

127 F. BRUNETIERE, L'Evolution des genres dans l'nistoire de la littérature, Paris, 1890. 


\section{JAIME SILES}

a él, por los formalistas rusos. Estos-subre todo, Tomasevskij ${ }^{128}$ y Propp ${ }^{129}$ - intentaron ( $y$, en lo relativo a la morfología del cuento ruso, lo consiguieron) una formulación y sistematización de las tipologías genéricas, a partir de lo que ellos llamaban la "noción dominante", consistente en ${ }^{130}$ "que los elementos descritos no sólo estén presentes, sino que también sean dominantes". Lo que les llevó a buscar no ya "las categorías del discurso literario, sino un determinado ideal de época, que puede encontrarse tanto en el autor --el cual siempre se refiere a cierto modelo de escritura, siquiera para transgredirla - como en el lector", para quien "se trata de un horizonte de expectativa, es decir, de un conjunto de reglas preexistentes que orientan su comprensión y le permiten una recepción apreciativa". Los formalistas rusos partían, además, de una serie de consideraciones, algunas de las cuales son válidas para la cuestión que aquí nos ocupa: la de los géneros literarios en la literatura latina. Estas consideraciones eran, entre otras, las siguientes $^{131}$ :

1) "Que el estudio de los géneros debe hacerse a partir de sus características estructurales y no a partir de sus nombres";

2) Que "los géneros forman, en el interior de cada período, un sistema" y que "no pueden definirse sino en sus relaciones mutuas". Lo que a su vez, les lleva a establecer otros dos postulados: 1) "que una obra no pertenece obligatoriamente a su género" porque "cada época está dominada por un sistema de géneros que no abarca forzosamente todas las obras" y 2) que lo que la historia literaria llama "período histórico-literario" no es sino "el predominio de un determinado grupo de rasgos, propios del discurso literario".

De este modo los formalistas intentaban dar una respuesta, científicamente elaborada, a las tres cuestiones que el estudio de la literatura plantea: a) la de definir las estructuras sincrónicas en sí mismas y no por clasificaciones o nomenclaturas ya establecidas y prefijadas; b) la de resolver el problema de la relación existente entre la entidad estructural y el fenómeno histórico; c) la de encontrar el "horizonte de expectativa", según el cual el público y el lector orientan la "comprensión" de la obra y, en consecuencia, la "recepción apreciativa" de la misma. La tentativa de los formalistas rusos - justo es reconocerlo- supone una aportación, tan interesante como valiosa, que ha de ser tenida en cuenta por la forma - tan organizada - en que aborda la problemática general que la investigación literaria tiene planteada. En este sentido, hay que subrayar:

1) que, por el modo de enfrentarse y responder a la cuestión de los géneros

128 B. TOMASEVSKIJ, Teorija literatury (Poètika), Moskva-Leningrad, 1925.

129 V.I. PROPP. Morfologija skazki (= Voprosy poètiki, XII), Leningrad, 1928.

130 Cf. DUCROT-TODOROV, op. cit., pág. 179.

131 Cf. DUCROT-TODOROV, op. cit., pp. 178-181. 


\section{NOTAS PARA UN ESTUDIO SISTEMATICO}

el formalismo ruso es una "Teoria Literaria";

2) que, por la forma de plantear y, a su manera, resolver el problema de la relación existente entre la entidad estructural y el fenómeno histórico, el formalismo ruso representa un método, muy particular, de entender y hacer la "Historia Literaria";

y 3) que, por tratar de encontrar - desde un punto de vista fundamentalmente intrinseco- el "horizonte de expectativa" del lector y del público, supone un intento, mucho más sólido que el de la sociología de la literatura, de hacer tanto Historia Literaria como Teoría de la Recepción.

Los formalistas rusos han contribuído, por otra parte y de manera eficiente, a distinguir los géneros de los tipos. Lo que nos permite situarlos dentro de ese Corpus teorético (integrado por Platón y Aristóteles, Jean Paul y Goethe, Staiger y Jakobson) que podemos considerar como el pensamiento, mejor fundamentado que, acerca de los géneros y su posible clasificación, tenemos. Sin embargo -y aunque insistimos en la relevancia de dicho movimiento- sus conclusiones pueden aplicarse mejor a la literatura contemporánea que a la antigüa. Esta -como dijimos- tiene a la Retórica como base teorético-conceptual y, por lo tanto, está condicionada por ella. Por otra parte, lo que el empeño de los formalistas deja entrever es una tentativa - velada y/o manifiesta- de construir una Retórica y una Poética como las clásicas que, según dijimos ${ }^{133}$ habían sido abandonadas por el espíritu romántico e historicista del siglo XIX. En este sentido, puede afirmarse que el formalismo ruso representa -como el $\mathrm{New}$ Criticism americano en poesía y el Círculo de Praga en lo relativo a la lengua literaria- una postura "neoclásica" y que, por lo tanto, sus conclusiones son aplicables al estudio de la literatura antigüa sólo en la medida en que, como los formalistas sostienen, "el género puede caracterizarse mediante un número variable de propiedades" y en la medida en que -como el estudio de la Retórica demuestra- las literaturas de la Antigüedad se acomodaron al paradigma de los géneros. De hecho, para el caso de la literatura latina ${ }^{134}$-en la que los géneros están definidos y sistematizados ya por la Retórica ${ }^{135}$ y forman un conjunto paradigmático anterior al escritor $^{136}$ y determinante del "horizonte de expectativa" del público- las conclusiones de los formalistas resultan utilizables sólo a nivel metodológico y crítico: no como explicación de los propios paradigmas. El método de los forma-

132 Cf. G. LUKACS, Sociologia de la literatura, traducción de M FABER-KAISER, Barcelona $1968^{2}$; M. HORKHEIMER, Teoría Crítica, traducción de J.J. DE SOLAR B., Barcelona, 1973.

133 Cf. supra. 2.2.1.

134 La cuestión es diferente en la literatura griega; CF. V. BUCHHEIT, Lintersuchungen zur Theorie des Genos epideiktikon, von Gorgias bis Aristóteles, München, 1960.

135 Cf. F. QUALBAUER, "Die genera dicendi bis Plinius d. j. ", Wiener Studien, 71 (1958), pp. 55 y 22.

136 Cf. E. LÖFSTEDT, "Reminiscence and Imitation. Some Problems in Latin Literature", Eranos, XLVII (1949), pp. 148-164. 


\section{JAIME SILES}

listas rusos es sumamente útil, en cambio, a la hora de inventariar y, sobre todo, describir dichos paradigmas, siendo de gran ayuda, también cuando se procede a establecer la "afinidad genérica" sobre el reconocimiento de funciones análogas. Así, por ejemplo, en el caso de la relación existente entre epopeya e historiografía. Pero, por lo general, la base teorética de las literaturas clásicas y, en concreto, de la latina, la constituye -como dijimos- la Retórica. Los géneros son, en la Antigüedad, estructuras linguísticas caracterizadas por un sistema de relaciones de interdependencia, que, en el interior de las mismas, se produce. Los ejes de dicho sistema son, fundamentalmente, dos: la espacialidad y la especiall$\mathrm{dad}^{137}$. La primera corresponde - $\mathrm{e}$ incluso puede identificarse - con lo que la Retórica Clásica denomina géneros literarios y que acaso fuese más conveniente denominar "textualidad", o, mejor, "espacio-en el texto-del discurso"; la segunda, indisolublemente unida a la primera, comprende $-\mathrm{y}$ se refiere- a todos y cada uno de los rasgos distintivos que, a nivel temático o de inventio y a nivel formal o de dispositio, definen o caracterizan la espacialidad del discurso. Según esto, cada espacio textual o género está caracterizado por una serie de propiedades "lingüisticas" (fonéticas, morfológicas, léxicas sintácticas y estilísticas), que, por decirlo así son de su exclusividad: de su especialidad, aunque también es cierto que las espacialidades son susceptibles de intertextualidad y que, en este sentido, también las especialidades son susceptibles de transvase: así, por ejemplo, en el caso de la sátira ${ }^{138}$ y en el de la novela ${ }^{139}$. La cuestión se complica aún más, con el problema de la llamada "teoría de los tres estilos"140 y, también, con el problema, tan debatido, del origen de los géneros, que no vamos a tratar aquí, aunque sí recordaremos las interesantes aportaciones hechas, en este sentido, por Nojgaard ${ }^{141}$-sobre la fábula antigüa-, por investigadores de orientación estructuralista, como Meleuc ${ }^{142}$ y Köngas-Maranda ${ }^{143}$ y, sobre todo, por Jo-

137 De la cuestión nos ocuparemos, más ampliamente, en nuestro trabajo titulado "Notas para un estudio sistemático de la literatura erótica barroca", Taller de Cultura I ( en prensa).

138 Cf. U. KNOCHE, Die römische Satire, Göttingen, 1957.

139 Cf. E. ROHDE, Der griechische Roman und seine Vorläufer, Leipzig, 1876 (Hidesheim, $1960^{4}$ ); E. Schwarz, Fünf Vortrüge über den griechische Roman, Berlín, 1896 (Berlín, $\left.1940^{2}\right)$; B. L.AVAGNINI, Studi sul romanzo greco, Messina-Firenze, 1950; B.E. PERRY, The Ancient Romances $=A$ Literary-historical Account of Their Originis, Berkeley, 1967, etc.; para una revision del tema Cf. C. GARCIA GUAL, "Idea de la Novela entre los gi iegos y romanos", Teoria de la Novcla, Edición de S. SANZ VILLANUECA y C.J. BARB ACHANO, Madrid, 1976, pp. 23-53.

140 Cf. E. FARAL, Les Arts poétiques du XII et du XIII siècle, Paris, 1924; A. FONTAN, "Los poemas virgilianos, los tres "stili" y la rota Vergili", Actas del III Congreso Español de Estudios Clásicos, 2 (Madrid, 1968), pp. 368-374.

141 Cf. M. NOJGAARD, La Fable Antique, 2 vols., Copenhague, 1964-1967.

142 S. MELEUC, "Structure de la maxime", Langages, 13 (1969), pp. 66-99.

143 E. KONGAS-MARANDA, “Structure des énigmes", L'Homme, IX, 3 (1969), pp. 5-48. 
lles ${ }^{144}$, quien explica los géneros-tipos a partir de un principio pluridimensional consistente en que, según él, las formas simples - que se encuentran, generalmente, en el folklore- son "extensiones directas de las formas lingüísticas" y "se convierten en elementos básicos de las obras de la "gran literatura"145. Por complicadas que estas cuestiones sean, lo cierto es que -como dijimos- la literatura latina tiene unas especialidades o géneros, a cada uno de los cuales corresponde, lingüística y temáticamente, una especialidad. La relación espacialidad-especialidad es paralela a (y subsidiaria de) la relación Sistema-subsistema. El subsistema representa, con respecto al Sistema, un ideolecto ${ }^{146}$; la especialidad ${ }^{147}$ es el idiolecto de la espacialidad. Pues bien, establecer la serie de relaciones existentes entre la Retórica y los géneros literarios, por un lado, y las espacialidades y las especialidades de la literatura latina, por otro, nos parece el modo más correcto de proceder no sólo en lo relativo a la descripción de la Morfología de los géneros que la informan, sino también en lo relativo a la estrecha relación existente entre la lengua y la literatura latina, porque -como advierte Trainà ${ }^{148}$ "il problema della formazione della lingua letteraria latina coesiste con quello della sua differenziazione, non solo dalla lingua parlata, ma anche secondo i generi letterari" ${ }^{149}$ Al describir las espacialidades, no hacemos, sino inventariar y describir las especialidades y viceversa: al inventariar las especialidades, no hacemos sino describir los rasgos distintivos (la Morfologia) de cada espacialidad. De ahí que el estudio

144 A. JOLLES, Formes Simples, Paris, 1972.

145 Cf. DUCROT-TODOROV, op. cit., pág. 184.

146 R.A. HALL, "Idioletto, Dialetto, Lingua", Studi Linguistici ịn onore di V. Pisani, I, (Brescia, 1969), pp. 515-528.

147 Para el concepto de "especialidad" me baso -aunque lo aplico en sentido distinto en: A. VAN GENNEP. "Essai d'une théorie des langues spéciales", separata de la Revue des Etudes Etnologiques et Sociologiques de Paris, 1908, pp. 1-11 (reeditado por Republications Paulet, Paris, 1968); J. COUSIN, "Les langues, spéciales", Mémorial Marouzeau, Paris, 1943, pp. 37-54; G. DEVOTO, Studi di Stilistica, Firenze, 1950, y Nouvi Studi di Stilistica, Firenze, 1962; W. WINTER, "Styles as Dialects", Proceedings IX Congress of Linguistics, La Haya, 1964, pp. 324 y. ss.; KOCH, "On the Principles of Stylistics", Lingua, 13 (1963), pp. 411 ss.; M. RIFATERRE, "Criteria for Style Analysis", Word, 15 (1959), pp. 154 ss., "Vers une définition linguistique du Style", Word, 21 (1961), pp. 318 y ss. y Essais de Stylistique Structurale, Paris, 1971; R. FOWLER, The Languages of Literature, London, 1971; Cf., también, L.R. PALMER, Introducción al latín, pp. 184 ss.; F. RODRIGUEZ ADRADOS, "La nueva linguística y la comprensión de la obra literaria", Cuadernos Hispanoamericanos, núms. 238-240 (octubre-noviembre 1969), pp. 55-70; F. LAZARO CARRETER, "La lingüística norteamericana y los estudios literarios de la década 1958-1968", Revista de Occidente 8 ('969), pp. 319-347.

148 Cf. "Riflessionni sulla Storia della lingua latina", apud STOLZ-DEBRUNNER-SCHMID, op. cit., p. XXIV.

149 Cf. además, PALMER, Introducción al latín, p. 102 ss. y G. DEVOTO, I fondamenti della storia linguistica, Firenze, 1951, pág. 77. 


\section{JAIME SILES}

morfológico de la literatura latina ${ }^{150}$-siempre que sea hecho por géneros y épocas y subrayando las relaciones existentes con la Retórica, que es su corpus teórico-conceptual- nos parezca el modo más correcto de estudiar el Sistema Literario Latino y de proceder a esa ordenación sincrónico-diacrónica del mismo, que todavía está por realizar.

\section{CONSIDERACION FINAL: NOTAS PARA UN ESTUDIO SISTEMATICO DE LA LITERATURA LATINA:}

De todo lo antedicho se deduce que el estudio de la Literatura Latina debe hacerse - desde el punto de vista intrinseco- a tres niveles:

a) uno, sincrónico, centrado en el análisis y consideración de los elementos constitutyos (los géneros literarios y su Morfologia) y determinantes (la Retórica y su corpus teorético-conceptual) del Sistema Literario Latino;

b) otro, diacrónico, centrado en la descripción de la variabilidad formal y el dinamismo, que, a lo largo de su historia, dicho Sistema experimenta;

y c) por último, un tercero, síntesis de los otros dos, que podemos denominar "ordenación sincrónico-diacrónica" del Sistema Literario Latino.

Desde el punto de vista extrínseco, $-\mathrm{y}$ habida cuenta de que toda obra literaria "es un signo en el sistema de signos literarios, culturales, sociales de una determinada época o situación"151 y que, por tanto, la Literatura Latina es un significante de la civilización en que surgió y que sólo, dentro de $-\mathrm{y}$ por referencia a-dicha civilización, tiene significado- el estudio de la Literatura Latina presupone la consideración, también, de causas "externas" a la misma, pero que, de algún modo, intervienen en $-o$ afectan a- su desarrollo o su constitución. Dentro del estudio extrinseco, cabe situar, pues, tanto factores históricos (socio-políticos, culturales, económicos), como biográficos, psicológicos, etc. El estudio extrínseco de la Literatura -es evidente- no tiene valor real en sí y, por lo tanto, los resultados que, del mismo, se obtengan no tienen entidad considerados en sí mismos: la adquieren sólo, cuando, por referencia al estudio intrínseco de la literatura, contribuyen a elucidar algún aspecto concreto y tangencial de la misma. Sin embargo, tampoco puede negarse su importancia, sobre todo, en un caso como el de la literatura latina, en el que cualquier dato o información, que aumente nuestro conocimiento de la misma, debe - por tangencial o mínimo que seaser aceptado. En este sentido $-\mathrm{y}$ aunque seamos partidarios del estudio intrinseco de la literatura - no podemos dejar de admitir la colaboración -al menos, subordinada o auxiliar - que el estudio extrinseco - muchas veces- supone y apor-

150 Un buen ejemplo de ello es el libro de H. RAHN, Morphologie der antiken Literatur, Darmstadt, 1969.

151 Cf. supra 1.3.1. 


\section{NOTAS PARA UN ESTUDIO SISTEMATICO}

ta. Por otra parte, es evidente que "el método estructural y funcional o como queramos llamarlo, resulta tan insuficiente como necesario para establecer los caracteres de un género, y para situar una obra concreta en la trayectoria histórica del mismo"152. De ahí que -en lo que al estudio de la literatura latina se refiere-postulemos, por un lado, una síntesis, que sea ordenación sincrónica-diacrónica de los elementos y las estructuras que la determinan, la constituyen y la informan, $\mathrm{y}$, por otro, propongamos -en lo que a la oposición estudio intrínseco/ estudio extrinseco se refiere- una solución flexible ${ }^{153}$, consistente en conceder, al estudio extrinseco un nivel subordinado y, al intrinseco un nivel subordinante y subordinador. De este modo, aunque establecemos una jerarquía entre ellos, mantenemos, sin embargo, una gradación que nos parece necesaria: la de que el estudio intrinseco, por ser el estudio de la obra en sí, debe ocupar un nivel superior al del extrinseco, que es el estudio de la obra por referencia a lo que no está en ella, a lo que no es ella. Ahora bien, en una cultura unitaria, tan compacta como la latina, el haz de relaciones que se establece entre lo "interno" y lo "externo", lo "intrínseco" y lo "extrínseco" es bastante más amplio y profundo de lo que, en un principio, se podría pensar. La Historia misma de la lengua latina puede servir de ejemplo ilustrativo de lo que estamos indicando. Y, como en la tengua, también en la literatura hay determinantes "externos" que debemos considerar. En este sentido, esa posible "storia sincronica", definida por Devoto ${ }^{154}$ como "una storia concentrata in un periodo ristrettissimo di tempo, ma comprensiva di tutti gli aspetti di una societá", tal vez fuera la forma de situar el Sistema Literario Latino y el conjunto de sus estructuras sincrónicas en su contexto histórico preciso, con el objeto de extraer, a partir de esa "situación", toda la gama de relaciones existentes entre lo "interno" y lo "externo" a la literatura latina. Pero, sin olvidar que, por muy determinante y condicionador que lo "externo" sea, la literatura en sí, se reduce a la Obra en sí considerada, esto es, al espacio textual -en que se encuentra escrita - y a la Morfología y tradición de dicho espacio. Mas, de todos modos, a la hora de hacer la ordenación sincrónico-diacrónica de la literatura Latina se tendrá en cuenta, también, aquellos influjos "extrínsecos" y aquellas circunstancias "externas" que, de alguna manera, se supone han intervenido en la variabilidad formal o el dinamismo de la misma. Desde el punto de vista intrínseco, la cuestión que la Historia Literaria planteaba era la de "¿cómo cambian los géneros?"; desde el punto de vista extrínseco, la cuestión es "¿por qué cambian los géneros?" y "¿qué es lo que - desde fuera- hace que el género cambie?". Pues bien, el estudio de la Literatura Latina tendrá que hacerse en esas dos direcciones y sentidos, y entre esas dos preguntas y todas sus posibilidades de respuesta. Como

152 Cf. F. LAZAR

152 Cf. F. LAZARO CARRETER, Estudios de Poética, pag. 20.

153 Para el concepto de solución flexible, cf. Y. Malkiel, "Filología española y Linguística General", Actas del I Congreso Internacional de Hispanistas, Oxford, 1964, pp. 107-126.

154 Cf. G. DEVOTO, "Storia politica e Storia linguistica", Aufstieg und Niedergang. . . . , II, 2, pag. 465. 


\section{JAIME SILES}

investigadores podemos optar por la dirección o sentido que -metodológicamente - nos parezca más científica, es decir, más correcta. Pero, procurando siempre no perder la posición ${ }^{155}$, ni aislar el subsistema del Sistema, pues, la lengua y la literaturas latinas -y el Sistema de la lengua y el de la literatura latina- son sólo signos de un Sistema Mayor que los engloba, al que unos llaman Latinität y otros Römertum ${ }^{156}$, y que, en cualquier caso, constituye una einheitliche Kultur que no es lícito diseccionar. $\mathrm{O}$ mejor, que hay que diseccionar para comprenderla, analíticamente, en todas sus partes y detalles. Pero que hay que recomponer sintéticamente, si se quiere entender de verdad la intima relación y la interdependencia existentes entre el Todo y cada una de sus partes, $y$ entre las diversas partes entre sí.

155 Aplicamos aquí un principio de la Física moderna: el llamado por Heisenberg (cf. Zeitschrift für Physik, 43 (1927), pág. 172 y del mismo, The Physical Principles of the Quantum Theory, Chicago, 1930) "principio de incertidumbrre", consistente en la imposibilidad de aislar la estructura del núcleo, sin perder la posición del átomo.

156 Cf. M. Gelzer, "Das Römertum als Kulturmacht", Historische Zeitschrift, CXXVI (1922). pág. 189 ss.; E. Fränkel, Die Stellung des Römertums in der humanistischen Bildung, Berlin, 1926; H. Dahlman, "Römertum und Humanismus", Studium Generale, I (1948), pp. 78-83; R. Heinze, Vom Geist des Römertums, Darmstadt, 1972; K. Büchner, Humanistas Romana, pág. 271; O. Seel, Römertum und Latinität, Stuttgart,1964. 